\title{
Elaboração da farinha de Passiflora edulis Sims (maracujá amarelo) a partir do exocarpo e o estudo da composição centesimal
}

\section{Elaboration of the Passiflora edulis Sims flour (yellow passion fruit) from the exocarpo and the centesimal composition study}

\author{
Layse Machado Jinkings ${ }^{1}$, Ivanna Santos Gonçalves ${ }^{2}$, Anne do Socorro Santos da Silva ${ }^{3}$ \\ ${ }^{1}$ Acadêmica de Nutrição. Faculdade Estácio. Macapá-AP Brasil. https://orcid.org/0000-0002-4355-8309. E-mail: \\ ivannagoncalves061@hotmail.com \\ ${ }^{2}$ Acadêmica de Nutrição. Faculdade Estácio. Macapá-AP Brasil. https://orcid.org/0000-0001-7169-8934. E-mail: laysejinkings@hotmail.com \\ ${ }^{3}$ Nutricionista, Instituto de Pesquisas Cientificas e Tecnológicas do Estado do Amapá. Macapá-AP Brasil. https://orcid.ora/0000-0001-5524- \\ 8095 E-mail: annedosocorro@hotmail.com
}

\author{
Palavras-chave \\ Casca \\ Composição centesimal \\ Farinha \\ Maracujá
}

\begin{abstract}
O maracujá Amarelo (Passiflora edulis Sims) é um fruto com características arredondadas, de cor amarelada, sua planta é trepadeira, lenhosa, perene, que possui um crescimento contínuo e suas raízes são superficiais. 0 IBGE destacou em seus dados coletados em 2017 a produção de maracujá no Brasil no ano de 2016, que foi de 703.489 toneladas e no ano de 2006 a quantidade produzida no município de Macapá/AP foram de 148 toneladas. A casca do maracujá amarelo possui em sua composição vários nutrientes que tem ação benéfica para o organismo, dentre eles a fibra (pectina). Alguns pesquisadores destacaram em seus artigos que a casca do maracujá amarelo é um alimento funcional, por possuir propriedades nutricionais de alto valor para o bem estar. O objetivo desse trabalho é elaborar uma farinha a partir do exocarpo do Maracujá Amarelo, e estudar sua composição centesimal. Os métodos utilizados para a análise da casca e da farinha foram, a determinação de umidade, cinzas, lipídeos (Bligh e Dyer), proteínas (Kjeldahl), carboidrato por diferença e valor calórico. As análises microbiológicas realizadas foram, as de Coliforme Termotolerantes e Salmonella sp. Os resultados para casca foram, umidade $85,34 \%$, cinzas $1,97 \%$, lipídeos $0,02 \%$, proteína 2,05\%, carboidratos por diferença 10,57 Kcal e valor calórico de 52,28 Kcal. Para a farinha feita do exocarpo do maracujá foram obtidos os seguintes resultados, umidade $7,65 \%$, cinzas $6,97 \%$, lipídeos $9,08 \%$, proteínas $4,89 \%$, carboidratos $71,00 \mathrm{Kcal}$ e valor calórico de 391,76 Kcal. Com tudo, a farinha elaborada neste estudo, pode ser uma fonte alternativa para o aproveitamento de resíduos orgânicos, por possuir aporte nutricional valioso na elaboração de produtos alimentícios alternativos.
\end{abstract}

\section{Keywords}

Peel

Centesimal composition

Flour

Passion fruit

\begin{abstract}
Yellow passion fruit (Passiflora edulis Sims) is a fruit with rounded characteristics, yellowish in color, its plant is climbing, woody, perennial, which has a continuous growth and its roots are superficial. In its data collected in 2017, IBGE highlighted the production of passion fruit in Brazil in 2016, which was 703,489 tons and in 2006 the amount produced in the municipality of Macapá / AP was 148 tons. The yellow passion fruit peel has in its composition several nutrients that have a beneficial action for the organism, among them fiber (pectin). Some researchers pointed out in their articles that the yellow passion fruit peel is a functional food, as it has nutritional properties of high value for well-being. The objective of this work is to prepare a flour from the yellow passion fruit exocarp, and to study its proximate composition. The methods used for the analysis of the shell and flour were the determination of moisture, ash, lipids (Bligh and Dyer), proteins (Kjeldahl), carbohydrate by difference and caloric value. The microbiological analyzes performed were those of Coliforme Termotolerantes and Salmonella sp. The results for bark were, humidity $85.34 \%$, ash $1.97 \%$, lipids $0.02 \%$, protein $2.05 \%$, carbohydrates by difference $10.57 \mathrm{Kcal}$ and caloric value of $52.28 \mathrm{Kcal}$. For the flour made from the passion fruit exocarp the following results were obtained, humidity $7.65 \%$, ash $6.97 \%$, lipids $9.08 \%$, proteins $4.89 \%$, carbohydrates $71.00 \mathrm{Kcal}$ and caloric value of $391.76 \mathrm{Kcal}$. However, the flour prepared in this study can be an alternative source for the use of organic waste, as it has a valuable nutritional input in the preparation of alternative food products.
\end{abstract}


frutos mais produzidos e comercializados mundialmente. De acordo com os dados coletados pelo IBGE em 2017, no ano de 2016 o Brasil produziu cerca de 703.489 toneladas de maracujá, e em 2007 foram cerca de 554,598 toneladas de maracujá, sendo a produção no município de Macapá (Amapá) com 148 toneladas (IBGE, 2017).

No Brasil são produzidos diariamente uma quantidade significativa de material orgânico em resíduo, pelas indústrias alimentícias, com isso, toneladas de materiais são descartados inadequadamente o que pode ser prejudicial ao ecossistema. Grande parte desses resíduos são gerados pela indústria extratora de sucos, que descartam no meio ambiente cascas, albedos, sementes, aparas e vesículas. No entanto esses substratos têm grande valor nutricional na sua composição química (NASCIMENTO et al., 2013).

A casca do maracujá vem se tornando um dos resíduos mais reutilizados, de acordo com Ishimoto et al. (2007), relatam sobre o aproveitamento dessas cascas na produção de biscoitos no intuito de aumentar as propriedades nutricionais do mesmo, como, a fibra, e sua aceitabilidade entre consumidores, destacando os resultados significativos e satisfatórios das análises, onde a fibra apresentou aproximadamente $7,5 \%$ comparado a outro biscoito similar que não teve adição da farinha feita do exocarpo do maracujá amarelo.

Em outros estudos foram analisados também a adição ou substituição da farinha elaborada a partir da casca do maracujá na elaboração de outros produtos alimentícios, como, Ozores, Storck E Fogaça (2015), relatam em seu artigo que fizeram um bolo com a adição de $10 \%$ da farinha da casca do maracujá, e obtiveram um resultado satisfatório, tanto na produção, como, na aceitabilidade e venda desse produto.

Fogagnoli e Seravalli (2014), abordam em seu artigo uma comparação com uma massa padrão e outra com uma massa adicionada a farinha de casca de maracujá e emulsificante, depois as compararam e ainda fizeram analises sensoriais com 79 provadores, resultando na aceitabilidade de ambas, sem ocorrer preferencias entre elas.

A RDC 12/2001 destaca os principais microrganismos que são analisados quando se elabora farinha a partir do exocarpo de frutas, e dois deles são: Coliformes termotolerantes e Salmonella sp. (BRASIL, 2001).

Está pesquisa teve como objetivo elaborar a farinha a partir do exocarpo do Maracujá Amarelo, Passiflora edulis Sims., e realizar o estudo centesimal tanto da casca quanto da farinha.

\section{MATERIAL E MÉTODOS}

Os maracujás foram adquiridos de um agricultor familiar na localidade do Bairro Novo Horizonte na cidade de Macapá no estado do Amapá/AP, localizado na região Norte, coord.: Lat.00 05' 16.7" N Long.: 51 02' 46.1' W. Os mesmos foram colhidos no período do mês de Junho de 2019, e em seguida, foram transportados para o Instituto de Pesquisas Cientificas e Tecnológicas do Amapá (IEPA), Núcleo de ciência e Tecnologia de Alimentos, dispondo do Laboratório Físico Química dos Alimentos, Usina de Óleo e Laboratório de Microbiologia, e a Faculdade Estácio de Macapá, dispondo do laboratório de Técnica Dietética e Bromatologia.

\section{Produção da Farinha a partir do exocarpo do Maracujá Amarelo}

Na Figura 1 está apresentado o fluxograma para a obtenção da farinha de $P$. edulis Sims.

Figura 1. Fluxograma de elaboração da farinha

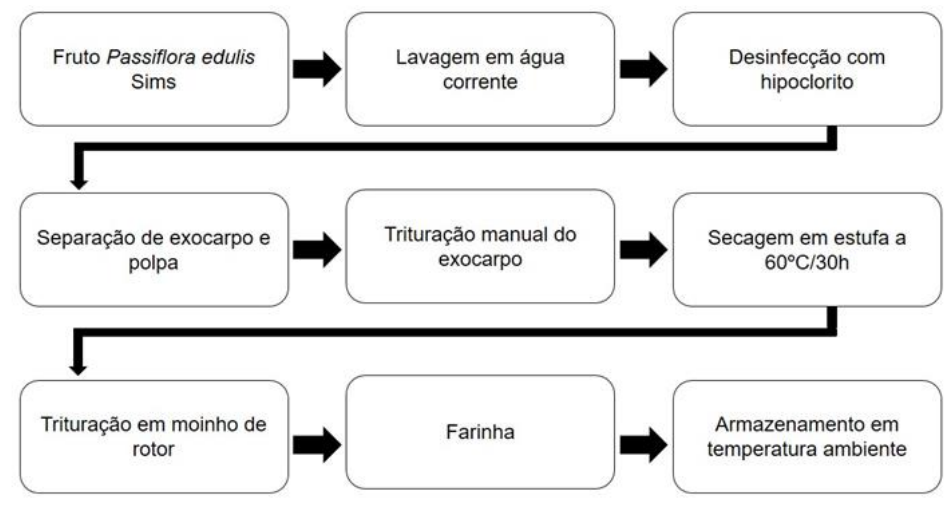

Após a colheita dos frutos de $P$. edulis Sims., os mesmos foram transportados para um local onde foi realizada a sua higienização, onde foram lavados com água corrente e deixados imersos em uma solução aquosa de hipoclorito de sódio à 200 ppm por 15 minutos. Depois da higienização, os frutos foram cortados manualmente com o auxílio de uma faca inox após assepsia com álcool 70\% (v/v), e em seguida, foram despolpados separando a casca da polpa. Logo após, as cascas foram cortadas novamente em pedaços pequenos para facilitar a secagem e a trituração em moinho (Figura 02).

Posteriormente foram colocadas em uma forma de alumínio inox e direcionadas para estufa á $60{ }^{\circ} \mathrm{C}$ por 30 horas, até completa desidratação. Após o processo de secagem, as cascas desidratadas foram moídas em moinho do tipo rotor (Figura 03). Obtendo-se a farinha do exocarpo de $P$. edulis Sims., em seguida, a farinha foi armazenada em 
embalagem plástica para alimentos e mantida em local seco, fresco e ao abrido da luz e calor.

Figura 2. Pré-preparo para elaboração da farinha

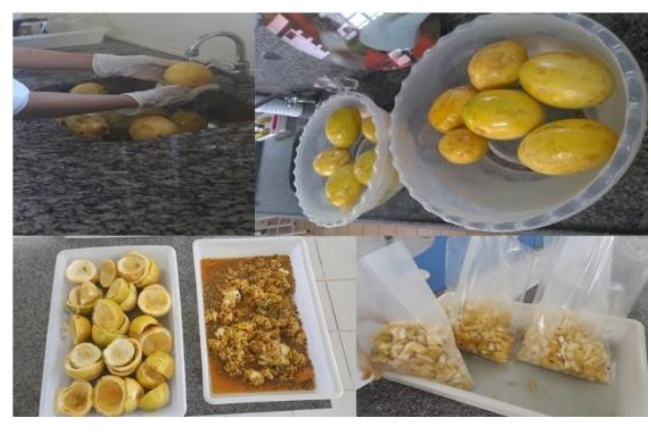

Figura 3. Obtenção da farinha

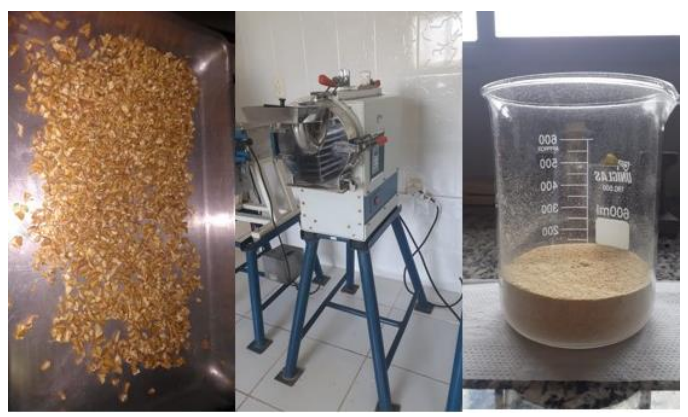

\section{Caracterização físico-química do fruto e farinha de P. edulis}

As análises realizadas foram para determinação dos teores de umidade, cinzas, lipídeos, proteínas, carboidratos por diferença e valor calórico.

A determinação do teor de umidade foi realizada em estufa com circulação de ar forçado conforme IAL (2008). Para determinação do teor de cinzas foi utilizado método de calcinação em mufla com temperatura de 580 ㅇ C conforme IAL (2008). A determinação da fração lipídica foi realizada a frio conforme descrito por Bligh e Dyer (1959). O teor de proteínas foi realizado pelo método de Kjeldahl, através da digestão ácida e destilação e titulação do nitrogênio total, e convertido para proteínas através do fator de correção de 6,25 conforme descrito por Menezes Filho et al. (2019). A porcentagem de carboidratos foi determinada por diferença conforme equação 1. Para quantificação do valor calórico total (VCT), seguiu conforme equação (2), descrita por IAL (2008).

$$
\% E=100-(A+B+C+D) \quad \text { Eq. (1) }
$$

Onde: $\mathrm{E}=$ carboidrato; $\mathrm{A}=$ proteína total; $\mathrm{B}=$ lipídeos; $\mathrm{C}=$ umidade; $D=$ resíduo mineral.

$$
\mathrm{VCT}=(\mathrm{E} \times 4)+(\mathrm{A} \times 4)+(\mathrm{B} \times 9) \quad \text { Eq. }(2)
$$

Onde: $\mathrm{E}=$ carboidrato; $\mathrm{A}$ = proteína total; $\mathrm{B}=$ lipídeos.

\section{Análises microbiológicas}

Foram realizados testes para determinação da presença ou ausência de Escherichia coli. Para o ensaio microbiológico, em Erlenmeyer, uma alíquota de $10 \mathrm{~g}$ de amostra farinácea do exocarpo de $P$. edulis, foi depositada. Em seguida foi adicionando $90 \mathrm{~mL}$ de água peptonada $\left(\mathrm{H}_{2} \mathrm{Op}\right)$. Em seguida, foi transferido $1 \mathrm{~mL}$ da solução para dois tubos contendo 9 $\mathrm{mL}$ de $\mathrm{H}_{2} \mathrm{Op}$ e mais $1 \mathrm{~mL}$ para outros três tubos contendo caldo Lauryl Sulfato Triptase (LST). Foram retirados $1 \mathrm{~mL}$ dos tubos com amostra e $\mathrm{H}_{2} \mathrm{Op}$ e transferidos para os três tubos, contendo caldo Lauryl Suflfato Triptose (LST). Após esse processo todas as amostras foram incubadas a 35 ㅇ C por 2448h. Verificado diariamente se havia produção de gases ou turvação do meio para dar prosseguimento as analises (ISO 7251, 2005).

Para a análise da presença ou ausência de Salmonella sp. Alíquota contendo $10 \mathrm{~g}$ da amostra farinácea foi homogeneizada em $90 \mathrm{~mL}$ de caldo Lactosado (STP), onde em seguida, foi levada para incubação a 35 ㅇ c por $24 \mathrm{~h}$. Posteriormente foram transferidos $100 \mu \mathrm{L}$ de caldo Lactosado para um tubo de ensaios contendo $10 \mathrm{~mL}$ de caldo Rappaport-Vassilidis Soja (RVS) e em seguida, incubados a 41,5 oc por $24 \pm 3 \mathrm{~h}$., observando se as amostras apresentavam alguma alteração indicando crescimento de microrganismos, para assim prosseguir com as análises (ISO 6579, 2007).

\section{Análise estatística}

Todas as análises foram realizadas em triplicata, com determinação da média aritmética seguida de \pm desvio padrão, o programa utilizado foi o Office Excel 2013.

\section{RESULTADOS E DISCUSSÃO}

Conforme a realização das determinações, os resultados obtidos da composição centesimal da casca in natura e da farinha, está apresentada na Tabela 1. As análises microbiológicas da farinha estão apresentadas na Tabela 2. $\mathrm{Na}$ Tabela 3 estão demonstrados alguns resultados de análises coletadas na literatura de referência para outras farinhas realizadas a partir do exocarpo de outras frutas.

0 resultado de umidade da casca in natura do maracujá obteve resultado de $85,34 \%$ e para a farinha da casca de $7,65 \%$. Ao comparar os resultados da casca com a farinha, demostrou-se que a aplicação da secagem realizada na casca apresentou resultado satisfatório, pois o mesmo conseguiu 
reduzir a quantidade de água e obter teor inferior a $15 \%$. Conforme RDC no 263/2005 preconiza que farinhas devem apresentar teor de umidade máximo de $15 \%$ (g $100 \mathrm{~g}^{-1}$ massa seca).

Comparado os resultados de cinzas da casca in apresenta maior tempo de prateleira, podendo ser estocada, sendo utilizada por um período longo, quando comparado ao produto in natura de uso imediato.

De acordo com os resultados obtidos nas análises microbiológicas para a farinha do maracujá, observou-se que

Tabela 1. Caracterização físico-química da casca do maracujá in natura e farinha a partir do exocarpo.

\section{Análises Casca do maracujá $\quad$ Farinha a partir do exocarpo}

\begin{tabular}{ccc}
\hline Umidade (\%) & $85,34 \pm 0,50$ & $7,65 \pm 0,20$ \\
\hline Cinzas (\%) & $1,97 \pm 0,49$ & $6,97 \pm 0,01$ \\
\hline Lipídeos (\%) & $0,02 \pm 0,25$ & $9,08 \pm 0,83$ \\
\hline Proteínas (\%) & $2,05 \pm 0,07$ & $4,89 \pm 0,62$ \\
\hline Carboidratos (kcal) & $10,57 \pm 0,42$ & $71,00 \pm 0,34$ \\
\hline Valor Calórico total (VET) & $52,28 \mathrm{Kcal}$ & $391,76 \mathrm{Kcal}$
\end{tabular}

Tabela 2. Resultados de análises microbiológica da farinhas da casca do Maracujá.

\begin{tabular}{cll}
\hline Análises & Farinha* & Legislação** \\
\hline Coliformes termotolerantes & $<3$ & $10^{2}$ UFC \\
\hline Salmonella sp. & Ausência & Ausência \\
\hline
\end{tabular}

natura e da farinha, observa-se que a farinha apresentou resultados de 6,97\%, superior ao resultado da casca in natura de 1,97\%. Conforme Webber Carvalho (2012), a secagem influenciou positivamente, pois a água presente na casca in natura inicial é superior ao encontrado na farinha, apresentando maior quantidade de água livre. Com isso a determinação de cinzas encontrada na farinha do exocarpo do maracujá teve um aumento significativo.

Ao comparar o valor de $9,08 \%$ que a farinha obteve nas determinações de lipídeos com o resultado que a casca apresentou de $0,02 \%$, observasse que o valor da farinha teve um acréscimo epopeico, na medida que retiramos a água presente nós alimentos, outros nutrientes ressaltam seu valor.

Os resultados obtidos através da determinação de proteína ao serem comparadas, observou-se que a farinha apresentou teor igual a 4,89\%, sendo superior ao observado na casca in natura de 2,05\%. Demostrando que a farinha possui um percentual de proteínas superior, podendo ser empregada na dieta rica em proteínas, no desenvolvimento de shakes, barras nutracêuticas e em adição em sucos naturais enriquecidos (MENEZES FILHO et al., 2019).

Ao comparar os valores de carboidratos da casca in natura 52,28 Kcal com a farinha 71,00 Kcal, observa-se um acréscimo satisfatório para a farinha. Com isso, a produção farinácea torna-se de grande importância, visto que, a mesma apresentou ausência de Salmonella sp., e para os resultados de coliformes termotoletantes estão abaixo de $<3$ UFC. A farinha obtida do P. edulis analisada, está dentro dos padrões microbiológicos e sanitários para alimentos conforme RDC 12/2001, sendo assim, através das boas práticas de fabricação apresentadas neste estudo, tornando possível o seu uso para consumo humano e animal.

No estudo realizado por Farias (2018), para composição centesimal da farinha da casca da romã (Punica granatum L.), o pesquisador obteve-se resultado de $10,56 \%$ para umidade. E no estudo realizado por Silva, Silva e Silva Júnior (2019) avaliando a composição da farinha da casca de mangostão (Garcinia mangostona L.) os pesquisadores obtiveram resultado de $22,04 \%$ de umidade, sendo superior ao resultado deste estudo. Já Vargas et al, (2012), os pesquisadores avaliando a farinha da casca da banana prata (Musa acuminata) verde apresentou teor de umidade de $4,78 \%$, inferior ao obtido neste estudo. Se deduz que por se tratar de frutas e características diferentes, os resultados se mostram divergentes.

Vargas et al, (2012) relataram em sua pesquisa o resultado de $6,88 \%$ de cinza na farinha elaborada a partir da casca da banana verde, que ao comparadas aos valores de cinzas do estudo com $6,97 \%$ ambas obtiveram resultados semelhantes. E já quando comparada o valor de cinzas do estudo com a de Farias, (2018) que obteve 3,83\% de cinzas 
da farinha da casca do romã, e de Silva, Silva e Silva Júnior, (2019) com 2,1\% de cinzas com a farinha da casca do mangostão, os valores apresentaram - se inferiores. Provável que a temperatura $550{ }^{\circ} \mathrm{C}$ utilizada no procedimento de cinzas da farinha da romã possa ter influenciado nessa diferenciação entre a da pesquisa deste relatório que foi de $580^{\circ} \mathrm{C}$.

Nunes et al, (2017) descreve em seu relatório sobre Influência da temperatura de secagem nas propriedades físico-química de resíduos - abacaxi, onde quanto maior for a temperatura utilizada nos procedimentos centesimais, haverá a concentração de alguns nutrientes.

A desidratação concentra alguns nutrientes e compostos, como os ácidos orgânicos, já que retira a água presente, que é um solvente universal. Posto isso podemos declarar que esse comportamento é perfeitamente aceitável, já que a temperatura influenciou o teor de água, com um menor teor de água temos aumento dos demais componentes (NUNES et al., 2017).

Conforme Farias (2018), Silva, Silva e Silva Junior (2019) e Vargas et al. (2012) ao comparar os valores de lipídeos $2,93 \%, 0,23 \%$ e $8,13 \%$, que analisaram a farinha obtida a partir do exocarpo de frutas romã, Mangostão e banana verde destacou-se valores inferiores ao da farinha da casca do maracujá amarelo. Essas diferenciações podem ter ocorrido pelo modo de plantio, colheita ou até mesmo maturação dos frutos.

A quantidade de proteína encontrada na casca da farinha de maracujá é $4,89 \%$, sendo superior ao da romã com $0,71 \%$ descrito por Farias, 2018, e inferior ao encontrado na farinha de exocarpo de banana verde com 5,09\% por Vargas et al. (2012), no mangostão de 5,11\% relatados por Silva, Silva e Silva Junior (2019), e outros autores como Vieira et al. (2017), não citados na tabela anterior apresentaram em seu estudo sobre Adição de farinha da casca de melão em cupcakes altera a composição físico-química e a aceitabilidade entre crianças, o valor de 10,84\% de proteína encontrada na farinha da casca do melão. Condizente a RDC $n^{\circ} 19 / 2010$, onde alega que a quantidade proteica que deve conter nos alimentos é entre $0,10 \%$ a 5,00\%, faz com que a farinha elaborada nesta pesquisa entre dentro dos padrões exigidos.

Rapina (2017), não citada na tabela 3, enuncia em seu estudo titulado Caracterização de farinhas de albedo, bagaço e casca de laranja e sua aplicação em bolos de laranja, o resultado de $17,00 \%$ de carboidratos encontrados na farinha da casca da laranja, e diante ao trabalho relatado por Silva, Silva e Silva Junior (2019) citado na tabela anterior, o mesmo retratou cerca de $70,19 \%$ de carboidrato na sua composição, comparando esses dois estudos ao desta pesquisa observamos que apresentaram proporções inferiores. Vargas et al. (2012) e Farias (2018) que também são citados na tabela 3 analisaram o teor de carboidratos na farinha do exocarpo de banana verde com $75,13 \%$ e romã $81,98 \%$ respectivamente, obtiveram seus valores superiores ao descrito no estudo com $71,00 \%$.

Segundo Garcia et al. (2014), os fatores que influenciam nos teores de frutos são: o tempo exposto ao sol, o modo de colheita, adubação utilizada no solo, clima, etc. Podemos analisar que essas alterações observadas podem estar ligadas a qualidade nutricional do fruto, o que pode futuramente modificar a composição da farinha ao utilizarmos a cascas dos mesmos para produzi-la.

\section{CONSIDERAÇÕES FINAIS}

Os resultados obtidos da farinha elaborada no estudo apresentaram características satisfatórias quanto à composição centesimal, comparada ao da casca in natura.

As alterações apresentadas entre ambas as mostras na determinação de umidade observou - se que a água presente nos alimentos acaba escondendo uma quantidade significativa de nutrientes, onde só através do processo de secagem consegue demostrar a concentração nutricional que os alimentos possuem. Além, do fator do excesso de umidade no produto, o clima também se destaca como um influenciador dessas alterações nutricionais.

A microbiologia realizada na farinha, foram analisadas Salmonella sp. e Coliformes Termotolerantes. Destacando-se que para Salmonella sp. apresentou ausência estando apropriada para o consumo humano, Coliformes Termotolerantes apresentou valores satisfatórias para os padrões higiênicos-sanitários. Ambas atendendo a legislação de acordo com a RDC 12/2001.

Com tudo, a farinha elaborada neste estudo, pode ser uma fonte alternativa para o aproveitamento de resíduos orgânicos, por possuir um aporte nutricional valioso na elaboração de outros produtos alimentícios.

\section{AGRADECIMENTOS}

A Profa. orientadora Anne do Socorro Santos da Silva pelo empenho dedicado à elaboração deste trabalho de pesquisa, ao agricultor familiar pela aquisição dos frutos, ao Instituto de Pesquisas Cientificas Tecnológicas do Amapá (IEPA) e a Faculdade Estácio de Macapá, pelo apoio e incentivo 
recebido para o desenvolvimento da pesquisa.

\section{REFERÊNCIAS}

BRASIL. ANVISA - AGÊNCIA NACIONAL DE VIGILÂNCIA SANITÁRIA. Resolução RDC no 263, 22 de setembro de 2005. Diário Oficial da União, Poder Executivo, 29 Agosto. 2005.

BRASIL. ANVISA - AGÊNCIA NACIONAL DE VIGILÂNCIA SANITÁRIA. Resolução RDC n 12, de 02 de janeiro de 2001. Diário Oficial da União, Poder Executivo, 10 Jan. 2001.

BRASIL. ANVISA - AGÊNCIA NACIONAL DE VIGILÂNCIA SANITÁRIA. Resolução RDC no 19, de 05 de maio de 2010. Diário Oficial da União, Poder Executivo, 06 Maio. 2010.

CARVALHO, W. Secagem de polpa residual obtida na industrialização de batata frita. Goiânia, p. 89 - 91, 2012.

FARIAS, M. Estudo da adição de polpa e farinha da casca de Romã (punica granatum I.) na qualidade de pães tipo forma. Fortaleza/CE, p. 13 - 68, 2018.

FOGAGNOLI, G; SERAVALLI, E, A, G. Aplicação de farinha de casca de maracujá em massa alimentícia fresca. Campinas, v. 17, n. 3, p. 204-212, jul./set. 2014 Disponível em https://search.proquest.com/openview/8f7410216d03b8 e9bdf7e15a12ca6995/1?pqorigsite=gscholar $\&$ cbl=20301 17. Acesso em: 24/11/2019.

GARCIA L. G. C.; VENDRUSCOLO F.; SILVA, F. A. Determinação do teor de água em farinhas por micro-ondas Revista Brasileira de Produtos Agroindustriais, Campina Grande, v.16, n.1, p.17-25, 2014.

GUARIENTI, L, M. et al, influência das temperaturas mínima e máxima em características de qualidade industrial e em rendimento de grãos de trigo. Ciênc. Tecnol. Aliment., Campinas, 24(4): 505-515, out.-dez. 2004. Disponível em: http://www.scielo.br/pdf/cta/v24n4/a05v24n4. Acesso em: 24/11/2019.

INSTITUTO BRASILEIRO DE GEOGRAFIA E ESTATÍSTICA - IBGE, Produção Agrícola Municipal - PAM, 2017.

IAL - INSTITUTO ADOLFO LUTZ. Procedimentos e Determinações Gerais. In: Zenebon,O.; Pascuet, N. S.; Tiglea, P. (Org.). Métodos físico-químicos para análise de alimentos. 4. ed. São Paulo: Instituto Adolfo Lutz, 2008, cap. 4, p. 83-158.

ISHIMOTO, F, Y. et al. Aproveitamento Alternativo da Casca do MaracujáAmarelo (Passiflora edulis f. var. flavicarpa Deg.) para Produção de Biscoitos. Revista Ciências Exatas e Naturais, Vol.9 no 2, Paraná, 2007. Disponível em: https://revistas.unicentro.br/index.php/RECEN/article/vi ew/85/120. Acesso em: 24/11/2019
ISO 7251:2005. Microbiology of food and animal feeding stuffs, Horizontal method for the detection and enumeration of presumptive Escherichia coli, Most probable number technique. Disponível em:<https://www.iso.org/standard/34568.html>. Acesso em: 16/06/2019.

ISO 6579-1:2007. Microbiology of the food chain, Horizontal method for the detection, enumeration and serotyping of Salmonella. Part 1: Detection of Salmonella spp. Disponível em: https://www.iso.org/standard/56712.html. Acesso em: 16/06/2019

LIMA, A, de, A. et al. A Cultura do Maracujá. (EMBRAPA-SPI. Coleção plantar, 13). Brasília, DF: EMBRAPA - SPI. 1994. p. 74.

MENEZES FILHO, A, C, P. et al. Parâmetros físico-químicos, tecnológicos, atividade antioxidante, conteúdo de fenólicos totais e carotenóides das farinhas dos frutos do jatobá-do-cerrado (Hymenaea stigonocarpa Mart. ex Hayne). Multi Science-Journal, Urutaí - GO, v. 2, n. 1, p. 93-100, 2019.

NASCIMENTO, E, M, G, C. et al. Benefícios e perigos do aproveitamento da casca de maracujá (Passiflora Edulis) como ingrediente na produção de alimentos. Rev Inst Adolfo Lutz. São Paulo. p. 72(1):1-9, 2013.

NUNES, J, S. et al. Influência da temperatura de secagem nas propriedades físico-química de resíduos abacaxi. AreiaPB, p.44, 2017.

OLIVEIRA, L, F. et al. Aproveitamento alternativo da casca do maracujá amarelo (Passiflora Edulis F.Flavicarpa) para produção do doce em calda. Cienc.Tecnol.Aliment. Campinas, vol.22, n.3, pp.259-262. 2002.

OZORES, B; STORCK, C, R; FOGAÇA, A, O. Aceitabilidade e características tecnológicas de bolo enriquecido com farinha de maracujá. Disciplinarum Scientia. Série: Ciências da Saúde, Santa Maria - RS, v. 16, n. 1, p. 61-69, $2015 . \quad$ Disponível em: https://periodicos.ufn.edu.br/index.php/disciplinarums/ article/view/1110/1052. Acesso em: 24/11/2019.

RAPINA, L. Caracterização de farinhas de albedo, bagaço e casca de laranja e sua aplicação em bolos de laranja. São José - Rio Preto, p. 53, 2017.

SILVA, D. C; SILVA, A. S. S.; e SILVA JUNIOR, A. C. S. Estudo físico-químico do fruto Garcinia mangostona L. e o desenvolvimento de uma farinha a partir do exocarpo. Revista Arquivos Científicos (IMMES). Macapá, AP, Ano 2019 , v. 2, n. 1, p. 59-66.

VARGAS, B, C. et al. Composição físico-quimica de farinha de casca e de polpa de banana verde. XVI Encontro Latino Americano de Iniciação Científica e XII Encontro Latino Americano de Pós-Graduação - Universidade do Vale do 
Paraíba. Alegre/ES, p. 01-05, 2012.

VITKOSKI, F. Estudo da influência do tempo de umidificação (condicionamento) do grão de trigo, nataxa de extração e parâmetros físico-químicos da farinha. Universidade Tecnológica Federal do Paraná Coordenação de Alimentos curso Superior em Tecnologia de Alimentos. Ponta Grossa, p. 09-23, 2015. Disponível em: http://repositorio.roca.utfpr.edu.br/jspui/bitstream/1/80 68/1/PG_COALM_2015_1_25.pdf. Acesso em: 24/11/2019.

VIEIRA, R. F. F. A., et al. Adição de farinha da casca de melão em cupcakes altera a composição físico-química e a aceitabilidade entre crianças. Formiga/ MG, p. 27-28. 2017.

Submissão: 09/03/2019

Aprovado para publicação: 25/06/2020 